\title{
Estimulando la cooperación en investigación nanotecnológica entre Europa y América Latina
}

\author{
INEKE MALSCH*
}

$\mathbf{L}$ a Comisión Europea desea estimular la cooperación en el desarrollo de la ciencia y tecnología entre investigadores de Europa y otras partes del mundo. Para impulsarla, los investigadores con orígen de alguno de los países miembro del International Cooperation Partner Countries (ICPC, por sus siglas en Inglés) ${ }^{1}$ fuera de la Unión Europea, pueden participar en proyectos de investigación financiados por ésta bajo el Séptimo Programa Marco para la Investigación y el Desarrollo Tecnológico (FP7, por sus siglas en Inglés). Los participantes de América Latina son elegibles aunque deben argumentar su contribución a las metas del FP7.

La falta de visibilidad de los investigadores latinoamericanos especializados en nanociencia y la nanotecnología en Europa, y la débil conciencia acerca de las oportunidades de financiación de la Unión Europea en América Latina, son los principales cuellos de botella que obstaculizan la cooperación. Para superar estos problemas, la Unión Europea financia acciones de apoyo, incluyendo el proyecto NanoForum Unión Europea - América Latina. Este proyecto ha organizado misiones y talleres en México y Brasil para identificar grupos de investigación, empresas y actividades del gobierno en nanociencias y nanotecnologías, con el fin de estimular la cooperación en la investigación. Aún más, 21 investigadores de diferentes países de América Latina han sido invitados a visitar un centro europeo de investigación en nanotecnología por un lapso máximo de tres meses a modo de explorar vías de colaboración de largo plazo. Son catorce investigadores mexicanos, tres argentinos, dos brasileños, uno colombiano y uno chileno.

Como ejercicio de seguimiento del proyecto, se ha realizado una breve visita a la comunidad de na- notecnólogos de Argentina en noviembre de 2007. Los informes de todos los eventos son publicados en la página del proyecto (www.nanforumeula.eu), así como en la de Nanoforum (www.nanoforum.org).

En 2008, el proyecto NanoNet del ICPC empezó. Éste es también financiado por la Unión Europea y tiene por objeto el desarrollo de:

- un repositorio electrónico, de acceso vía Internet, de publicaciones en nanociencia y nanotecnología.

- una base de datos de investigadores.

- un foro en línea.

Estos instrumentos están destinados a informar y facilitar la creación de redes entre la Unión Europea y el desarrollo de la investigación y la tecnología de los países miembros del ICPC. El proyecto tendrá una duración de cuatro años y es coordinado por el Instituto de Nanotecnología del Reino Unido (www. nano.org.uk). Entre los resultados esperados está el paquete de informes anuales sobre nanociencias y nanotecnologías en América Latina. Los investigadores de dicha región están, por tanto, invitados a presentar resultados de investigación de acceso abierto, así como los perfiles de sus grupos de investigación e intereses personales. El ICPC-NanoNet también organizará seminarios anuales que estarán abiertos a la participación de usuarios remotos a través de Internet.

\footnotetext{
* Administradora técnica del proyecto Nanoforum Unión Europea-América Latina y directora de Malsch TechnoValuation (Holanda; www.malsch.demon.nl).

${ }^{1}$ Para consultar la lista del ICPC, vea: http://cordis.europa.eu/ fp7/who_en.html\#countries
} 